\title{
Non specific S-T segment variations during intravenous induction in anesthesia in hypertensive patients treated with renin angiotensin system
} antagonists

\begin{abstract}
Background: induction in anesthesia and airway‘s manipulations are stressful events for patients undergoing surgery, producing consecutive changes in blood pressure and pulse rate. There are several reports indicating that hypertensive patients treated with Renin angiotensin system (RAS) antagonists show greater hemodynamic changes during these periods which may imply that coronary circulation is compromised and variations in the ST-T segment might be noticed. The aim of this study was to evaluate and report the ST changes appeared during intravenous induction to anesthesia in hypertensive patients.
\end{abstract}

Method and material: In prospective, randomized clinical study, Sixty patients undergoing elective surgery in general anesthesia, ASA I and II, BMI $<30 \mathrm{~m}^{2}$ were randomized into two groups: Group A included hypertensive patients, chronically treated with RAS antagonists $(\mathrm{n}=30)$ and Group B, included normotensive patients $(\mathrm{n}=30)$. Patients in both groups underwent standardized anesthesia induction protocol. In both groups we analyzed the changes of blood pressure, heart rate and non-specific ST changes (smaller than 0.1 $\mathrm{mm}$ ) at five times: T0 (ambulatory report); T1 -pre induction; T2 - after induction; T3 (at laryngoscopy), T4 (5 min after intubation) and T5 $10 \mathrm{~min}$ after intubation.

Results: The size of the ST segment at T0 was evidently different in both groups $(-0.21 \mathrm{~mm}+0.4$ vs. $-0.01 \mathrm{~mm}+0.2)$ but statistically insignificant $(\mathrm{p}>0.05)$. At T3 (during the laryngoscopy) there was no differences in the size of the ST segment between the study groups $(p=0.07)$. The main changes were found at T4: $-0.31 \pm 0.4$ vs. $-0.02 \pm 0.3(p=0.004427)$, 5 minutes after the intubation. It seems that this is a result of the stress reaction of the body on the laryngoscopy and due to the effects of the released catecholamines.

Conclusion: The laryngoscopy and the intubation of the hypertensive patients treated with RAS antagonists provoke a remarkable decrease of the BP that is responsible for a coronary vasoconstriction and changes in the size of the ST segment. The main changes in the ST segment are 5 minutes after the intubation.

Keywords: intubation, laryngoscopy, vasoconstriction, ECG, ST-T segment
Volume 8 Issue I - 2017

\author{
Marija Sholjakova,' Marija Jovanovski-Srceva ${ }^{2}$ \\ IDepartment for Doctoral studies University "Ss. Cyril \& \\ Methodius" Faculty of Medicine, Republic of Macedonia \\ 2University Clinic of Anesthesiology, University "Ss. Cyril \& \\ Methodius" Faculty of Medicine, Republic of Macedonia
}

Correspondence: Marija Sholjakova, Full professor of Anesthesiology, Department for Doctoral studies University Ss. Cyril \& Methodius $\square$ Faculty of Medicine, Bul. Marks I Engels I/5-16, I000 Skopje, Republic of Macedonia, Tel +389 71 2434 90, Fax +389 23110002 ,

Emailmarija.sholjakova@medf.ukim.edu.mk

Received: May 15, 2017| Published: May 25, 2017

\section{Introduction}

The induction of anesthesia combined with airway manipulations are stressful events for patients undergoing surgery. The consecutive hemodynamic changes are seen as impaired blood pressure (mostly as hypotension) and tachycardia. The hypertensive disease is followed by structural changes in the cardiovascular system and those patients are very sensitive to the influence of the anesthetics and anesthetic manipulations. Nowadays, the use of Renin angiotensin system (RAS) antagonists (angiotensin-converting enzyme (ACE) inhibitors, and angiotensin II receptor antagonists), as antihypertensive therapy, is in constant increase. In general, in anesthetic practice a continuation of the antihypertensive therapy until the morning of surgery is accepted. ${ }^{1-3}$ But, by the evidences it was confirmed that ACE is taken on the day of the surgery provoked a hypotension refractory to the therapy with sympathetic-agonists and fluids..$^{4-11}$ These data indicate that hypertensive patients treated with Renin angiotensin system antagonists (RASa) are more sensitive to anesthesia than the patients treated with beta blockers. ${ }^{1,12,13}$
Renin angiotensin system is an important system of the body, responsible for the maintenance of blood pressure during the stress. The treatment with RAS antagonists induce a blockade of the RAS that may affect hemodynamic during anesthesia and surgery. It seems that this hemodynamic disturbances compromise the coronary circulation producing variations in the ST-T segment. Trotter and his colleagues in 1992 have investigated the incidence of ST-segment abnormalities during Caesarean section under regional and general anesthesia. They found that significant myocardial ischemia is very infrequent in healthy patients undergoing elective Caesarean section. ${ }^{14}$ Recently, the opinions about the use of antagonist of RAS prior to surgery are still controversial. The appearance of changes in ST-T waves as a result of the stress during the induction to anesthesia is an indication of the harmful effect of this procedure. ${ }^{15}$ We hypothesized that normotensive patients are less sensitive to anesthetic stress during the induction to anesthesia and airway's manipulation than hypertensive patients treated with RASa. With the aim to confirm this hypothesis an investigation of the non-specific ST variations during the induction to anesthesia in hypertensive patients treated with Renin Angiotensin System Antagonists was performed. 


\section{Patients and method}

This prospective randomized study was committed at the University Clinic of Anesthesia, Reanimation and Intensive Care at the Medical Faculty at the University "Ss Cyril and Methodius" in Skopje, Republic of Macedonia, during 2014-2015. The written information consent was obtained from each patient enrolled in the study. In the study there were included 60 patients $(n=60)$ of ASA physical status I or II, that underwent general anesthesia for different surgical procedures. In accordance the blood pressure prior the surgery and the antihypertensive therapy, the sixty patients for general anesthesia were randomized into two groups: Group A-hypertensive patients treated with RASa $(n=30)$ and Group B - normotensive patients, without hypertension, $(n=30)$. Patients in both groups were anaesthetized with standard general anesthesia: induction with propophol, rocouronium and fentanyl and maintenance with sevoflurane, $\mathrm{N}_{2} \mathrm{O} / \mathrm{O}_{2} ; 60: 40$. A day prior to surgery a routinely pre-anesthetic checkups for physical status of the patients were done (physical examination of health condition, ASA evaluation and routine lab investigations). The NIBP, HR and 12 channels ECG strip were done to all patients included in the study, noted (T0) and analyzed for the existence of abnormalities (elevation / depression) of the ST segment. The hypertensive patients treated with RASa without any ECG abnormalities were selected for the trial. After the explanation of the procedure and the approval of the written consent they received an advice to omit the morning dose of the RASa drug. All enrolled patient $(n=60)$ a light sedation received evening and morning medication of midazolam (2 mg PO).

After the entrance in the preoperative area 5-leads ECG monitoring, non-invasive blood pressure (NIBP), heart rate (HR), respiratory rate (RR) and oxygen saturation $\left(\mathrm{pSO}_{2}\right)$, started to be monitored and continued during the surgical procedure. An intravenous line in cephalic vein was secured. Prior to procedure at "T1" baseline BP, HR and ECG strip, were obtained. The hemodynamic parameters were measured and documented five times during the induction and the airway's manipulations T1-T5. Monitoring of the ST segment - The electrodes for each patient were placed as follows: right arm (RA) electrode - second intercostals space right to sternum, left arm (LA) electrode - second intercostals space left to sternum and left leg (LL) electrode - V5 position. J point was calibrated individually and all non-specific ST changes (smaller then $0.1 \mathrm{~mm}$ ) were automatically recorded from bipolar lead II from Datex (Ommeda) monitor. The hemodynamic changes (NIBP and HR) and the non-specific ST changes (smaller than $0.1 \mathrm{~mm}$ ) were recorded and analyzed five times $\mathrm{T} 1$ - T5. Analysis were reported for: T 0 - base line, measured in the outpatient checkup; $\mathrm{T} 1$ - before induction (1 minute after the vein line was secured); T 2 - after the IV induction of anesthesia, (1 minute after the lost of the corneal reflex); T 3 - at laryngoscopy; T4 - 5 minutes after intubation; $\mathrm{T} 5$ - before incision (10 minutes after the intubation). The demographic characteristics of the patients enrolled in the study are presented in the Table 1. From the Table 1 it is clear, that the patients in the two groups are homogenous. There are insignificant differences in sex, age, religion and Mallampati characteristics in the studied groups.

Table 2 is presenting the distribution of the type of RASa drugs and the time when it was omitted prior to surgery. The values of the blood pressure (BP) and heart rate as mean and SD are presented in the Table 3. There is a significant difference in BP in the preoperative checkup (T0) in the groups. Despite the antihypertensive treatment, the patients in the hypertensive group have high BP. It was slightly decreased preoperatively (T1), but a decrease $>20 \mathrm{~mm} \mathrm{Hg}$ was noted after the induction to anesthesia (T2). The airways manipulations as stressed procedure did not provoke changes in the study group A and $B$. There were not noted any remarkable differences in the groups $(\mathrm{p}=0.3)$. But in T 4 and T 5, 5 and 10 minutes after the induction, the BP dropped in the bout groups. The hypotension was developed in the group A (decrease of $\mathrm{BP}>30 \mathrm{mmHg}$ ). The degree of dropping of BP in the Group A vs. Group B was statistically significantly bigger $(p<0.05)$. There were significant differences in BP between the groups in T0, T1, T2 and T5 (Table 3). The variations of the ST-T segments on the ECG monitors of the studied groups are presented in the Table 4. The average values of the ST segment in the group A (hypertensive patients) were from -0.2 to $-0.3 \mathrm{~mm}$, with remarkable differences from the non-hypertensive patients (Group B) where the range was from -0.003 to $0.007 \mathrm{~mm}$. The ST variations less than $0.2 \mathrm{~mm}$ were noted as non-specific variations. There is a significant difference in the appearance of the ST segment in the study group at T1, T4 and T5. According the ANOVA - test, the differences of the mean values of the ST segments registered in the groups are insignificant, $\mathrm{p}>0.05$ (Tb.6)

Table I Demographics of the study groups

\begin{tabular}{|c|c|c|c|}
\hline Parameter & Group A $(n=30)$ & Group B $(n=30)$ & $\mathbf{p}$ \\
\hline Sex M/F & $10 / 20(33.3 \% / 66.6 \%)$ & $14 / 16(46.6 \% / 53.3 \%)$ & $p=0.2938$ \\
\hline Age $(M \pm S D)$ & $53.366 \pm 7.327$ & $44.466 \pm 9.354$ & $p=0.1234$ \\
\hline $\mathrm{BMI}>25 \%(\mathrm{~N} / \%)$ & $25(83.3 \%)$ & $19(63.3 \%)$ & $p=0.0863$ \\
\hline Religion Musl/ Christ & $10 / 20$ & $6 / 24$ & I \\
\hline \multicolumn{4}{|l|}{ Mallampati (N/\%) } \\
\hline I & $13(43.3 \%)$ & $15(50 \%)$ & $p>0.05$ \\
\hline II & $17(56.6 \%)$ & $15(50 \%)$ & $p>0.05$ \\
\hline
\end{tabular}

Table 2 The type of the antihypertensive drugs received prior to surgery

\begin{tabular}{lll}
\hline & $\mathbf{N}$ & $\%$ \\
\hline ACEI & 26 & 86.66667 \\
ACE+ARB & 4 & 13.33333 \\
\hline
\end{tabular}

\begin{tabular}{lll}
\hline Hours & $\mathbf{N}$ & $\%$ \\
\hline$<12 \mathrm{~h}$ & 23 & 76.7 \\
$>=12 \mathrm{~h}$ & 7 & 23.3 \\
\hline
\end{tabular}

\section{Discussion}

The impact of ST segment monitoring on the patients' outcomes is not known, but this is a useful method for detecting non-specific ST variations or silent ischemia in patients undergoing surgical procedures. In order to obtain accurate data in ST segment, monitoring the assurance of the locations of the electrodes from removal is important. ${ }^{16-19}$ The baseline must be stable and not wandering. There should be little interference from skeletal muscle. The patient must be relaxed and comfortable. There should be a square wave calibration to show that $1 \mathrm{mV}$ is equivalent to $1 \mathrm{~cm}$ in height. The identification of the ischemic events is preferably with monitoring of ST segment changes in multiple leads (12 leads), but during the surgery the use of 5 lead monitors is common. ${ }^{20}$ The appearance of the ST segment at lead II and V of the ECG is with high sensitivity to detect coronary ischemia. ${ }^{21}$ As significant depression or elevation of ST segment is considered a variation of at list $0-1 \mathrm{mV}$ or $1 \mathrm{~mm}$. These changes are mostly presented in the coronary attacks or in hypertensive patients with uninspected hypotension or tachycardia. ${ }^{22}$ In this study a significant ST depression $(\mathrm{p}<0.05)$ was found in the group of hypertensive patients treated with RAS antagonist without other characteristic changes, particularly without any clinical and anamnesis sign regarding the presence of an acute coronary attack. With a careful analysis of the 
degree of ST depression and the character and depth of inversion of the $\mathrm{T}$ waves, were found correlations between these findings with developed hypotension $(>30 \mathrm{mmHg})$ in the Group A. There are several reports about the interaction of hypotension in patients who received angiotensin-converting enzyme inhibitors (ACEIs) before a surgical procedure, suggesting that interactions between ACEIs and anesthesia may be neither beneficial nor predictable. ${ }^{23-27}$ The answer of such hypotension is hidden in the pharmacology of the antagonist of RAS.
The RAS antagonists produce vasodilatation via several mechanisms: a direct sympathetic blockade, increases the half life of the peptides of vasodilatation (bradikinins, prostaglandins), inhibitions of the angiotensin 2 (AT-2), decrease release of aldosteron and ADH with consecutive impairment of the retention of $\mathrm{Na}$ ion and water. The vasoconstrictor activity of RAS, via (angiotensin) AT-2 is disabled and the stress-responses of the regional circulation and the control of the endothelial tonus is decreased. ${ }^{28,29}$

Table 3 The hemodynamic changes in the groups in different times

\begin{tabular}{|c|c|c|c|c|c|c|}
\hline \multirow[b]{2}{*}{ Time [Time] } & \multicolumn{3}{|c|}{ Heart rate/ bpm (M士SD) } & \multicolumn{3}{|c|}{ Blood pressure / mmHg (M士SD) } \\
\hline & Group A $(n=30)$ & Group B $(n=30)$ & $\mathbf{p}$ & Group A ( & Group B ( & $\mathbf{p}$ \\
\hline t 0 & $82.0 \pm 17.8$ & $84.8 \pm 13.3$ & 0.27719 & $157.2 \pm 18.5$ & $131.0 \pm 14.3$ & $0.000001 *$ \\
\hline $\mathrm{t} \mathrm{I}$ & $80.9 \pm 17.0$ & $82.3 \pm 13.2$ & 0.473347 & $148.3 \pm 16.3$ & $127.0 \pm 14.3$ & $0.000005^{*}$ \\
\hline t 2 & $79.6 \pm 16.5$ & $84.3 \pm 14.6$ & 0.193249 & $129.7 \pm 22.3$ & $119.8 \pm 14.3$ & $0.014413 *$ \\
\hline t 3 & $80.6 \pm 16.5$ & $87.2 \pm 13.5$ & 0.059429 & $120.7 \pm 27.6$ & $120.0 \pm 14.3$ & 0.300712 \\
\hline t 4 & $80.7 \pm 16.3$ & $81.4 \pm 13.0$ & 0.706172 & $103.6 \pm 21.9$ & $111.0 \pm 14.3$ & 0.344046 \\
\hline t 5 & $79.1 \pm 16.4$ & $80.9 \pm 15.1$ & 0.584363 & $95.0 \pm 21.5$ & $108.4 \pm 14.3$ & $0.015639 *$ \\
\hline
\end{tabular}

p $<0.05$ significant difference

Table 4 ST segment variation in the groups

\begin{tabular}{|c|c|c|c|c|c|}
\hline \multicolumn{6}{|c|}{ ST / mm study group A } \\
\hline Time & Valid N & Mean & Minimum & Maximum & Std.Dev. \\
\hline $\mathrm{TO}$ & 30 & -0.21 & -1.2 & 0.6 & $0.475 \mathrm{I} 4 \mathrm{I}$ \\
\hline T I & 30 & -0.223333 & -1.2 & 0.8 & 0.451575 \\
\hline T 2 & 30 & -0.203333 & -1 & 0.9 & 0.460497 \\
\hline T 3 & 30 & -0.24 & -1.2 & 0.6 & 0.503505 \\
\hline T 4 & 30 & -0.313333 & -1.2 & 0 & $0.47831 \mathrm{I}$ \\
\hline T 5 & 30 & -0.246667 & -1.4 & 0.7 & 0.502911 \\
\hline \multicolumn{6}{|c|}{ ST / mm Study Group B } \\
\hline T 0 & 30 & -0.013333 & -0.4 & 0.7 & 0.278832 \\
\hline T I & 30 & 0.006667 & -0.6 & 0.8 & 0.347338 \\
\hline T 2 & 30 & -0.016667 & -0.7 & 0.6 & 0.331229 \\
\hline T 3 & 30 & -0.003333 & -0.7 & 0.9 & 0.390829 \\
\hline T 4 & 30 & -0.023333 & -0.6 & 0.8 & 0.341077 \\
\hline T 5 & 30 & 0.003333 & -0.6 & 0.9 & $0.33986 \mathrm{I}$ \\
\hline
\end{tabular}

Table 5 Presentation of the Mann-Whitney U Test of the ST differences in groups

\begin{tabular}{llllll}
\hline $\mathbf{m m}$ & Rank Sum-Groupa & Rank Sum-Groupb & $\mathbf{U}$ & $\mathbf{Z}$ & p-level \\
\hline T 0 & 813.5 & 1016.5 & 348.5 & -1.50062 & 0.133455 \\
T I & 780 & 1050 & 315 & -1.9959 & $0.045946^{*}$ \\
T 2 & 798.5 & 1031.5 & 333.5 & -1.72239 & 0.085001 \\
T 3 & 794 & 1036 & 329 & -1.78892 & 0.073629 \\
T 4 & 722.5 & 1107.5 & 257.5 & -2.846 & $0.004427^{*}$ \\
T 5 & 760.5 & 1069.5 & 295.5 & -2.28419 & $0.02236 I^{*}$ \\
\hline
\end{tabular}

$\mathrm{P}<0.05$ significant differences

Table 6 Analysis of Variance - ANOVA test of the ST segment

\begin{tabular}{lllllllll}
\hline Groups & SS Effect & df & MS Effect & SS Error & df & MS Error & F & P \\
\hline Group A & 0.238278 & 5 & 0.04766 & 39.93167 & 174 & 0.229492 & 0.207656 & 0.958932 \\
Group B & 0.021111 & 5 & 0.00422 & 20.088 & 174 & 0.115448 & 0.036572 & 0.999273 \\
\hline
\end{tabular}

The developed hypotension is emphasized by the drugs used in the induction of anesthesia and is refractory to the therapy with sympathetic-agonists. In this study the morning intake of the RASa was avoided (more than 12 hours), but despite of this, a remarkable hypotension was noted. We speculate that the reason for this was the using of RASa; in this study the majority of the patients received ACEI's (26/4). It could be taken into consideration also, that during this hypotension the coronary blood supply is impaired, and a misbalance between the myocardial oxygen demand and its utilization is developed. ${ }^{30,31}$ In this short period of time the myocardium suffers from ischemia which is seen as a down-sloping ST- depression existing in this study from minimum -0.6 to maximum of $-1.2 \mathrm{~mm}(\mathrm{M}=0.3)$. The size of the ST segment at T0 was evidently different in both groups $(-0.21 \mathrm{~mm} \pm 0.4$ vs. $-0.01 \mathrm{~mm} \pm 0.2)$, but statistically insignificant ( $>0.05$ ), what was expected considering the diagnoses (hypertensive vs. normotensive). At the time T3 (during the laryngoscopy) there was noted no difference in the size of the ST segment between the study groups $(p=0.07)$. The main changes were found at T4: $-0.31 \pm 0.4$ vs. $-0.02 \pm 0.3\left(\mathrm{p}=0.004427^{*}\right), 5$ minutes after the intubation. It seems that this is a result of the stress reaction of the body on the laryngoscopy and due to the effects of the released catecholamine. 


\section{Conclusion}

The laryngoscopy and the intubation of the hypertensive patients treated with RAS antagonists provoke a remarkable decrease of the $\mathrm{BP}$ that is responsible for a coronary vasoconstriction and changes in the size of the ST segment. The main changes in the ST segment are 5 minutes after the intubation. None of the size of the ST abnormality was in the ranges for serious myocardial ischemia. According to the received results of ST segment in this study, we found that they did not match the criteria for ischemia in electrocardiography (less than $1.0 \mathrm{~mm}$ at $80 \mathrm{~min}$ after J point), and we concluded with the statement that these ST-segment changes are nonspecific abnormalities.

\section{Acknowledgements}

None.

\section{Conflicts of interest}

The authors declare that there is no conflict of interest

\section{References}

1. Fleisher LA, Beckman JA, Brown KA, et al. ACC/AHA 2007 Guidelines on perioperative cardiovascular evaluation and care for noncardiac surgery: executive summary. $J$ Am Coll Cardiol. 2007;50(17):17071732 .

2. Smith I, Jackson I. Beta-blockers, calcium channel blockers, angiotensin converting enzyme inhibitors and angiotensin receptor blockers: should they be stopped or not before ambulatory anaesthesia? Current Opinion in Anesthesiology. 2010;23(6):687-690.

3. Bertrand M, Godet G, Meersschaert K, et al. Should the angiotensin II antagonists be discontinued before surgery? Anesth Analg. 2001;92(1):26-30.

4. Mirenda VJ, Grissom TE. Anesthetic Implication of the reninangiotensin System and angiotensin - Converting Enzime Inhibitors. Anesth Analg. 1991;72(5):667-683.

5. Behnia R, Molteni A, Igic R. Angiotensin-converting enzyme inhibitors: mechanisms of action and implications in anesthesia practice. Curr Pharm Des. 2003;9(9):763-776.

6. Cittanova ML, Zubicki A, Savu C, et al. The chronic inhibition of angiotensinconverting enzyme impairs postoperative renal function. Anesth Analg. 2001;93(2):1111-1115.

7. Coriat P, Richer C, Douraki T. Influence of chronic angiotensinconverting enzyme inhibition on anesthetic induction. Anesthesiology. 1994;81:299-307.

8. Brabant SM, Bertrand M, Eyraud D, et al. The hemodynamic effects of anesthetic induction in vascular surgical patients chronically treated with angiotensin II receptor antagonists. Anesth Analg. 1999;89(6):13881392

9. Matchar DB, McCrory DC, Orlando LA, et al. Systematic review: comparative effectiveness of angiotensin-converting enzyme inhibitors and angiotensin II receptor blockers for treating essential hypertension. Ann Intern Med. 2008;148:16-29.

10. Costa VV, Caldas CA, Nunes NGL, et al. Influence of Angiotensinonverting Enzyme inhibitors on Hypotension after anesthetic induction. Is the Perioperative discontinuation of this drug Necessery? Revist Bras de Anest. 2009;59(6):710-732.

11. David LR, Hossain S, Krol M, et al. Predictors of Hypotension After Induction of General Anesthesia. Anesth Analg. 2005;101(3):622-628.

12. Bertrand M, Godet G, Meersschaert K, et al. Should the angiotensin II antagonists be discontinued before surgery? Anesth Analg. 2001;92(1):26-30.
13. Kheterpal S, Khodaparast O, Shanks A, et al. Chronic angiotensinconverting enzyme inhibitor or angiotensin receptor blocker therapy combined with diuretic therapy is associated with increased episodes of hypotension in noncardiac surgery. $J$ Cardiothorac Vasc Anesth. 2008;22(2):180-186.

14. Trotter TN, Langton A, Barker P, et al. Perioperative continuous monitoring of ST-segment changes in patients undergoing elective Caesarean Section. British Journal of Anaesthesia. 1992;69(4):352-355.

15. Righetti A, Crawford MH, O'Rourke R, et al. Detection of Perioperative Myocardial Damage after Coronary Artery Bypass Graft Surgery. Circulation. 1977;55(1):173-178.

16. Drew BJ, Califf RM, Funk M, et al. AHA Scientific Statement: Practice standards for electrocardiographic monitoring in hospital settings. Circulation. 2004;110(17):2721-2746.

17. Sheppard LP, Channer KS. Acute coronary syndromes. Contin Educ Anaesth Crit Care Pain. 2004;4(6):175-180.

18. Fredberg CK, Zager AE. Nonspecific" ST and T-Wave Changes. Circulation. 1961;23:655-661.

19. Johnson. AACN, Practice alert. ST segment monitoring. 2009:1-4.

20. Jari A Laukkanen, Timo H Ma"kikallio, Rainer Rauramaa, et al. Asymptomatic ST-segment depression during exercise testing and the risk of sudden cardiac death in middle-aged men: a population-based follow-up study. Eur Heart J. 2009;30(5):558-565.

21. Elhendy A, van Domburg RT, Bax JJ, et al. The Significance of StressInduced ST Segment Depression in Patients With Inferior Q Wave Myocardial Infarction. J Am Coll Cardiol. 1999;33(7):1909-1915.

22. Coriat $\mathrm{P}$, Richer $\mathrm{C}$, Douraki $\mathrm{T}$, et al. Influence of chronic angiotensinconverting enzyme inhibition on anesthetic induction. Anesthesiology. 1994;81(2):299-307.

23. Juan Carlos Villalba G. Electrocardiographic changes in the ST segment during anesthesia: Things to consider. Rev Colomb Anestesiol. 2012;40(3):175-176.

24. Rodrigez LBH, Batista A, Monteiro F, et al. ST-segment elevation during general anesthesia for non-cardiac surgery: a case of Takotsubo. Brazilian Journal of Anesthesiology. 2015;65(5):403-406.

25. Singh PM, Shah D, Trikha A. Recurrent intraoperative silent ST depression responding to phenylephrine. J Anaesthesiol Clin Pharmacol. 2012;28(4):510-513.

26. Dominiak P. Modulation of sympathetic control by ACE inhibitors. Eur Heart J. 1993;14(Suppl 1):169-172.

27. Gombar S, Khanna AK, Gombar KK. Perioperative myocardial ischaemia and infarction - a review. Indian J Anaesth. 2007;51(4):287.

28. Mandim BLS, Achá RES, Fonseca NM, et al. Cardiac arrhythmias and ST changes in the perioperative period of elderly patients submitted to transurethral prostatectomy under spinal anesthesia. Comparative study. Rev Bras Anestesiol. 2004;54(2):1-11

29. Yang JH, Hahn JY, Bin Song Y, et al. Angiotensin receptor blocker in patients with ST segment elevation myocardial infarction with preserved left ventricular systolic function: prospective cohort study 349. 2004.

30. Colson P, Ryckwaert F, Coriat P. Renin Angiotensin System Antagonists and Anesthesia. Anesthesia \& Analgesia. 1999;89(5):1143-1155.

31. Brabant S, Bertrand M, Eyraud D, et al. The Hemodynamic Effects of Anesthetic Induction in Vascular Surgical Patients Chronically Treated with Angiotensin II Receptor Antagonists. Anesth Analg. 1999;89(6):1388-1392. 